\title{
DIRETRIZES PARA CONCEPÇÃO DE CURSOS EM EAD
}

\author{
SÃO JOSÉ/SC JULHO/2018
}

\author{
Andreza Regina Lopes da Silva - IPDAAL - contato@andrezalopes.com.br \\ Juliana Bordinhão Diana - UFSC - juliana.bdiana@gmail.com \\ Fernando José Spanhol－ UFSC - profspanhol@gmail.com
}

Tipo: Investigação Científica (IC)

Natureza: Relatório Final de Pesquisa

Categoria: Gerenciamento e Logística

Setor Educacional: EDUCAÇÃO SUPERIOR, EDUCAÇÃO CORPORATIVA, EDUCAÇÃO CONTINUADA EM GERAL

\begin{abstract}
RESUMO
O objetivo neste artigo é apresentar diretrizes para concepção de cursos em EaD que contribuam com o desenvolvimento de competências do aprendiz. Como procedimento metodológico trabalhou-se com abordagem exploratória-descritiva e análise qualitativa. A coleta de dados emergiu da pesquisa bibliográfica e documental. O método foi o indutivo a partir de uma orientação teórico-prática. Como resultado identificou-se dimensões fundamentais a serem contempladas na concepção de recursos educacionais iniciando pelo projeto instrucional do curso. Ou seja, a necessidade da visão sistêmica desafia profissionais e pesquisadores da área.
\end{abstract}

Palavras-chave: Educação a Distância. Planejamento. Gestão. 


\section{INTRODUÇÃO}

A Educação a Distância (EaD) tornou-se frequente no cenário educacional a partir da evolução e uso intensivo das tecnologias e mídias digitais e expandiu de forma intensa a partir do século XXI, quando assumiu força de política pública. Desde então o incentivo ao desenvolvimento de recursos educacionais que contribuam com a construção do conhecimento e consequentemente com o desenvolvimento de competências têm sido assunto de atenção àqueles que promovem cursos nesta modalidade. Esta discussão é multidisciplinar e destaca-se em diferentes áreas de estudo que bordam a qualidade da oferta de cursos nesta modalidade. Os recursos educacionais são artefatos de mediação na construção do conhecimento, processo fundamental da educação contemporânea, já que o conhecimento não se limita a espelhar uma teoria, mas a desenvolver competências a partir da ressignificação que o indivíduo dá ao saber compartilhado a partir do contexto vivido, repleto de diversidade (MORIN, 2000). Neste sentido, o objetivo neste artigo é apresentar diretrizes para a concepção de cursos na modalidade a distância com vista a contemplar uma proposta de desenvolvimento de competências técnicas e pedagógicas do aprendiz. Para tanto, partiu-se de uma abordagem exploratória-descritiva para compreender a complexidade dos elementos integrados na concepção de cursos na modalidade a distância (MARCONI; LAKATOS, 2010). Em seguida trabalhou-se da análise de múltiplos casos, a partir de registros técnicos e informacionais, resultantes da participação dos autores em projetos $\mathrm{EaD}$, na área de produção de recursos educacionais, desenvolvidos no período entre 2011 e 2017, em instituições brasileiras públicas e privadas, na perspectiva de educação formal e informal.

Para a organização e análise dos dados, tomou-se por base o conceito de ideia central, definido por Lefevre e Lefevre (2012), como a descrição sintética e de uma expressão apresentada. A análise dos resultados seguiu a abordagem qualitativa com o objetivo de reconhecer os fenômenos do estudo em profundidade. De modo complementar o método definido para esta pesquisa, de natureza teórico-prática, foi o indutivo permitindo aos autores a proposição das diretrizes enquanto fenômeno de concepção de um curso na modalidade a distância. Todo processo de indução seguiu a estruturação de Marconi e Lakatos (2010) organizada em três etapas: observação do fenômeno; descoberta da relação entre eles; generalização da relação. Esta organização foi trabalhada com fluidez integrando a discussão teórica, que se apresenta na unidade dois deste estudo, integrada a observação e vivencia prática dos autores na área que somam um caminhar de mais de uma década no contexto. Por fim, destaca-se a relevância e originalidade do resultado aqui apresentado e construído a partir do aperfeiçoamento, por meio do acervo da área, em relação a prática deste universo. 


\section{TRILHA TEÓRICA}

Os recursos educacionais na $\mathrm{EaD}$ assumem um papel de destaque, pois nesta modalidade a aprendizagem é em grande parte autônoma e os indivíduos precisam estar motivados, serem independentes, organizados e proativos. Como destaca Litto (2010), engana-se quem imagina que estudar a distância é mais fácil do que presencial. Nesse sentido, para planejar um curso na modalidade a distância não se deve imaginar que tal prática limita-se ao transpor do conteúdo do ensino presencial para a EaD. $\mathrm{O}$ desenvolvimento dos recursos educacionais para $\mathrm{EaD}$ envolve diferentes aspectos que podem ser contemplados na concepção do curso, que por sua vez pode ser organizado a partir de um projeto instrucional. Silva (2017) elucida que o projeto instrucional pode ser entendido como um primeiro documento estruturado da proposta do curso e para tanto deve contemplar questões relacionadas a necessidade de aprendizagem, objetivos de ensino e também descrição de possíveis limitações. Romiszowski e Romiszowski (1998) definem o este projeto instrucional como elemento relevante na concepção do sistema de ensino-aprendizagem e de todos os seus aspectos operacionais a serem adquiridos ou elaborados. Assim, destaca-se que um recurso educacional só pode ser considerado de qualidade e relevante quando este se encontra organizado e programado (AUSUBEL, 2000). Silva (2013-2017) corrobora que a qualidade do recurso educacional esta relacionada a sua potencialidade de promover a construção do conhecimento e para tanto deve ter forma, conteúdo, linguagem e atividades planejadas com base no perfil do aluno, na proposta do curso e nas competências a serem desenvolvidas. O desenvolvimento de competências - conceito que surgiu na França por volta de 1990 - transcende o saber que vai além da formação o que é fundamental na sociedade contemporânea, uma sociedade baseada no conhecimento onde a prática reflexiva é fundamental. Competência é "um saber agir responsável e reconhecido [...] que agreguem valor econômico à organização e valor social ao indivíduo." (FLEURY; FLEURY, 2001, p. 188). Assim, define-se que o projeto instrucional não se limita a ementas e bibliografias este documento deve principalmente trabalhar com a descrição de elementos como: público alvo, objetivo de ensino e aprendizagem, carga horária do curso e das disciplinas, estrutura do curso, tipos de mídias e avaliações adotadas, sistema de certificação entre outros elementos que precisam estar em consonância com o projeto pedagógico do curso e as competências esperadas. Perrenoud (2000) destaca que a competência é desenvolvida a partir de um conjunto de recursos cognitivos, uma rede de conhecimentos, aplicado a determinada situação prática.

Esta orientação impõe a necessidade de atentar para a disposição de recursos educacionais planejados de modo a potencializar a interação entre os diferentes atores envolvidos no projeto a fim de assegurar os direitos dos aprendizes (BRASIL, 
2007-2017). Para atender a estes aspectos os recursos educacionais em cursos EaD devem ser aderentes ao objetivo de ensino-aprendizagem e concepção pedagógica 0 que exige a interação de diferentes atores, intersecção de diversos processos e tecnologias de modo a se ter recursos educacionais enquanto unidades de conhecimento e não meras unidades de transmissão de informação. Dessa forma, o desenvolvimento efetivo de competências, exige na EaD um planejamento sistêmico levando em conta a estrutura institucional, o sistema de mídias e interação bem como o sistema político e administrativo que norteiam a instituição (GUIMARÃES; CARVALHO, 2015). Moran (2010) aponta que são dois os modelos de comunicação que regem o planejamento de um curso $\mathrm{EaD}$. Ou a comunicação ocorre a partir da participação tradicional do professor aparecendo em videoaula ou aula gravada, prática que pode ser somada a integração de leituras e atividades. Ou a comunicação ocorre por meio de recursos educacionais, impressos ou digitais, escritos de forma dialogada. E neste limiar, na fase de planejamento do curso, a concepção de recursos educacionais é elemento de ordem e alguns fatores influenciarão o bom desempenho do curso, como: concepção a partir do perfil do aluno; desenvolvimento a partir da experiência e conhecimento da equipe multidisciplinar; aptidões para escrita do conteúdo; escolha de tecnologia apropriada; acompanhamento e avaliação da proposta desenvolvida (SILVA, 2007; GUIMARÃES; CARVALHO, 2015; SILVA; 2017). Toda esta discussão é destacada por Silva (2017) como uma necessidade emergente da sociedade contemporânea que se caracteriza por uma conexão em rede em contínua transformação. Logo, somente a experiência com cursos presenciais não garante a qualidade da produção de recursos educacionais adequados à educação a distância dada as suas singularidades. É preciso compreender a EaD a partir de um "cuidadoso planejamento, um trabalho sistêmico e envolvimento de uma equipe multidisciplinar" (GUIMARÃES; CARVALHO, 2015, p. 6).

\section{TRILHA EMPÍRICA}

A visão de planejamento sistêmico na EaD é um componente de extrema importância quando se fala em oferta de um curso de qualidade que potencialize o desenvolvimento de competências do aprendiz. Ou seja, o planejamento é um dos principais elementos relacionados ao sucesso de um curso. Nesse sentido, é necessário conhecer e analisar as necessidades de aprendizagem e, a partir da identificação do objetivo do curso este se torna um exercício relevante a ser adotado como primeiro passo, devendo estar descrito na organização do projeto instrucional que apresenta os principais elementos de um projeto instrucional. O Quadro 1, elaborado a partir da concatenação teóricoempírica apresenta elementos e informações necessárias à construção do projeto instrucional. 


\begin{tabular}{|c|c|}
\hline Elementos & Informações necessárias \\
\hline Curso & $\begin{array}{l}\text { Qual a temática central do curso? Qual o nome } \\
\text { do curso? }\end{array}$ \\
\hline Introdução & Qual o contexto de desenvolvimento do curso? \\
\hline Objetivo & Qual o objetivo de formação do curso? \\
\hline Público-alvo & Quem são os possíveis alunos desta demanda? \\
\hline Bibliografia & $\begin{array}{l}\text { Qual a bibliografia básica necessária para } \\
\text { atender o objetivo do curso? }\end{array}$ \\
\hline Metodologia & $\begin{array}{l}\text { Qual serão os procedimentos empregados para } \\
\text { promover o ensino e a aprendizagem? Por } \\
\text { exemplo: terá acompanhamento de tutoria ou é } \\
\text { autoinstrucional? }\end{array}$ \\
\hline Materiais & $\begin{array}{l}\text { Quais recursos educacionais serão utilizados? } \\
\text { Exemplo: vídeo, livro digital, narrativa? }\end{array}$ \\
\hline Estrutura do curso & $\begin{array}{l}\text { Qual a organização didática pedagógica? Por } \\
\text { exemplo, será organizado em módulos divididos } \\
\text { por temática? }\end{array}$ \\
\hline Avaliação & $\begin{array}{l}\text { Existe previsão de avaliação? Em caso } \\
\text { afirmativo: será presencial ou on-line? Por } \\
\text { módulo? }\end{array}$ \\
\hline Carga horária & $\begin{array}{l}\text { Qual a carga horária necessária para realizar o } \\
\text { curso? Por exemplo: } 4 \text { módulos, cada módulo } \\
10 \text { horas -> total: } 40 \text { horas. }\end{array}$ \\
\hline Cronograma & $\begin{array}{l}\text { Qual a data de inicio e fim do curso? De cada } \\
\text { módulo? }\end{array}$ \\
\hline Certificação & $\begin{array}{l}\text { Será emitido certificado de aproveitamento? } \\
\text { Será disposto no ambiente virtual certificado de } \\
\text { participação? }\end{array}$ \\
\hline Modelagem da produção & $\begin{array}{l}\text { Existe uma equipe alocada para esta } \\
\text { demanda? Os recursos educacionais serão } \\
\text { desenvolvidos em parceria com outra } \\
\text { instituição? }\end{array}$ \\
\hline
\end{tabular}

Quadro 1 - Elementos essenciais de um projeto instrucional

Esta organização em treze elementos, definidos como diretrizes para o planejamento de um projeto instrucional, parte de uma análise das ideias centrais identificada nos relatórios e registro de participação dos autores em projetos diversos de âmbito nacional ofertados na modalidade a distância em cenários públicos e privados. Reconhece-se 
que para uma organização efetiva destes elementos é fundamental a participação de uma equipe multidisciplinar com experiência e conhecimento na oferta de cursos nesta modalidade. Assim, infere-se que conceber cursos de qualidade em EaD é um processo que exige uma prática interdisciplinar e não disciplinar ou modular de interesses isolados. A singularidade de oferta de curso na modalidade a distância implica diretamente no tempo necessário e nos elementos essenciais à elaboração de recursos educacionais de modo que estes não atuem como transmissores de informação, mas sim como construtores de conhecimento, refletindo diretamente na formação de competências sejam estas individuais ou organizacionais. De modo complementar, destaca-se que é importante ir além e considerar a elaboração de um padrão de referência para o volume dos recursos educacionais a serem disponibilizados para o aluno, pois como destaca Morin (2000) a educação contemporânea integra ao ensino e a aprendizagem o viver. Sendo assim, a partir da experiência e boas práticas, dos autores, descreve-se no Quadro 2 uma proposta referencial de como trabalhar com a quantidade dos recursos educacionais com vista a qualidade da formação, o desenvolvimento de competência e um desenvolvimento do indivíduo como ser humano que integra uma vida a ser vivida.

\begin{tabular}{|l|l|l|}
\hline \multicolumn{1}{|c|}{ Elementos } & \multicolumn{1}{|c|}{ Referências } & \multicolumn{1}{c|}{ Exemplo } \\
\hline Carga horária & 20 horas & 20 horas/aula \\
\hline Unidades de aprendizagem & $\begin{array}{l}1 \text { unidade para cada 10 } \\
\text { horas/aula }\end{array}$ & 2 unidades \\
\hline e-book & De 2 à 3 páginas por hora/aula & $\begin{array}{l}40 \text { a } 60 \text { páginas em editor de } \\
\text { texto. }\end{array}$ \\
\hline Apresentação em telas & De 3 à 4 telas (slides) por hora. & $\begin{array}{l}60 \text { a } 80 \text { telas em arquivo de } \\
\text { apresentação. }\end{array}$ \\
\hline Vídeo & $\begin{array}{l}\text { Estima-se que o aluno mantem Até } 4 \text { vídeos de } 8 \text { minutos. } \\
\text { boa concentração para vídeo } \\
\text { entre } 3 \text { e } 5 \text { minutos. Podendo } \\
\text { chegar ao máximo a } 8 \text { minutos. }\end{array}$ & \\
\hline
\end{tabular}

Quadro 2 - Referência de elaboração de recursos educacionais e carga-horária

Esta organização tem a pretensão de auxiliar principalmente iniciantes na área de produção de um curso nesta modalidade visto que a teoria ainda não dispõe de discussão neste sentido. Logo, independente da mídia estes elementos citados são orientativos ao processo de concepção dos recursos educacionais que potencialize o desenvolvimento do aprendiz. Neste sentido, destaca-se que a concepção de recursos educacionais para cursos $\mathrm{EaD}$ inclui atividades complexas e intensivas em 
conhecimento, como evidenciado nas pesquisas de Silva (2013; 2017). Assim, sugerese que este processo envolva a atuação interdisciplinar de uma equipe multidisciplinar com profissionais como: professor conteudista, designer educacional, revisor, designer gráfico, programador de ambiente virtual, analista de plágio e gestor multidisciplinar, sendo que estas duas últimas atividades citadas podem ser desenvolvidas por outro profissional como o designer educacional - um júnior e outro pleno ou sênior, por exemplo. Considera-se ainda que para atender de modo sistêmico, congruente e efetivo os diferentes processos e atividades na produção dos recursos educacionais são importantes os conhecimento relacionados a estimativa de tempo das diferentes atividades. Uma referência foi organizada, a partir dos registros dos autores, no Quadro 3. Entende-se que a mesma pode ser customizada, quando necessário, e ajustada ao longo do processo, pois a EaD além de requerer um planejamento sistêmico exige, frente as suas singularidades, uma estrutura flexível. Neste meandro para direcionar um planejamento inicial de produção de recursos educacionais mapeou-se os principais processos e prazos a seguir.

\begin{tabular}{|l|l|}
\hline Processo & Prazos \\
\hline Elaboração de conteúdo & 20 a 30 dias para disciplinas com carga horária de \\
& 60 horas/aula. \\
\hline Analise de plágio & 1 hora para cada 20 páginas de texto. \\
\hline Design Educacional & 4 horas para cada 20 páginas de texto. \\
\hline Revisão & 4 horas para cada 30 páginas de texto. \\
\hline Design Gráfico & $\begin{array}{l}4 \text { horas para cada } 60 \text { páginas de texto, havendo necessidade } \\
\text { de tratamento de imagens sugere-se acrescentar } 1 \text { hora. }\end{array}$ \\
\hline Roteirizarão & $\begin{array}{l}7 \text { dias para fase de produção e } 5 \text { dias para edição para cada } 2 \\
\text { páginas de conteúdo inicial, previsão de } 8 \text { min. de vídeo. }\end{array}$ \\
\hline Programação de AVEA & $\begin{array}{l}30 \text { dias para organização de um curso de baixa complexidade } \\
\text { (até } 40 \text { horas). }\end{array}$ \\
\hline Gestor multidisciplinar & 4hs/diária para um curso de até 80hs, média complexidade. \\
\hline
\end{tabular}

Quadro 3 - Processos e prazos da produção de recursos educacional

Sugere-se que a adequação destas práticas ao contexto do projeto pode ser feita de forma efetiva por um profissional experiente em educação e gestão, ou seja, um profissional multidisciplinar, como, um designer educacional. O uso de softwares de gestão também pode contribuir. Contudo, percebe-se que tais ferramentas disponíveis no mercado não contemplam tal especificidade e precisam ser customizadas. A especificidade se dá em âmbito de processos e atividades que não seguem um fluxo linear e precisam ser consideradas por serem intensivas em conhecimento. Para 
aqueles que estão iniciando, ou tem demanda pontual de projetos, uma alternativa é mapear e utilizar planilha eletrônica de dados compartilhada com a equipe do projeto de modo que se tenha em tempo real mapeada a integração desses passos. A partir dos elementos apresentados e discutidos, no presente estudo, organizou-se, com base nas percepções conceituais, documentais e aspectos empíricos vivenciados pelos autores, 0 Quadro 4 com quatro dimensões específicas, com critérios definidos para orientar a concepção de um curso na modalidade a distância que promova o desenvolvimento de competências.

\begin{tabular}{|c|c|c|}
\hline Dimensões & Critérios & Justificativa \\
\hline \multirow[t]{4}{*}{ Projeto } & Objetivo do curso & \multirow{4}{*}{$\begin{array}{l}\text { Define os parâmetros e elementos essenciais à } \\
\text { elaboração dos recursos educacionais, congregando } \\
\text { aspectos essenciais a um projeto educacional } \\
\text { organizado com data de inicio e fim pré-definidos. }\end{array}$} \\
\hline & Carga horária & \\
\hline & Público-alvo & \\
\hline & Metodologia & \\
\hline \multirow{3}{*}{\begin{tabular}{|l} 
Recursos \\
educacionais
\end{tabular}} & Organização & \multirow{3}{*}{$\begin{array}{l}\text { Relacionado ao conteúdo e mídias que irão contribuir } \\
\text { com o ensino e a aprendizagem de acordo com o } \\
\text { objetivo do projeto. }\end{array}$} \\
\hline & Mídias utilizadas & \\
\hline & Volume de material & \\
\hline \multirow[t]{9}{*}{ Pessoas } & Gestor & \multirow{9}{*}{$\begin{array}{l}\text { Relação dos principais profissionais envolvidos na } \\
\text { aconcepção e elaboração dos recursos educacionais } \\
\text { aque serão disponibilizados aos alunos. }\end{array}$} \\
\hline & Professor conteudista & \\
\hline & Designer Educacional & \\
\hline & Revisor & \\
\hline & Designer Gráfico & \\
\hline & Programador & \\
\hline & Ambiente Virtual & \\
\hline & Roteirista & \\
\hline & Analista de plágio & \\
\hline \multirow[t]{2}{*}{ Processos } & Fluxo de produção & \multirow{2}{*}{$\begin{array}{l}\text { Descreve os processos e estimam-se os prazos } \\
\text { previstos para o trabalho da equipe a fim de apresentar } \\
\text { à instituição um material que esteja de acordo com o } \\
\text { previsto cujo maior desafio é potencializar a construção } \\
\text { do conhecimento do aluno e consequentemente } \\
\text { desenvolver competências. }\end{array}$} \\
\hline & Prazos & \\
\hline
\end{tabular}

Quadro 4 - Critérios para concepção de cursos na modalidade a distância

Com esta compreensão evidencia-se a discussão teórica proposta por autores como Guimarães (2015) que alertam a necessidade de trabalhar com planejamento sistêmico quando se busca a concepção de um curso na modalidade a distância. Neste sentido, 
com vista a contribuir com o avanço teórico-prático na área entende-se que as diretrizes descritas e sistematizadas em quatro dimensões favorecem a concepção e desenvolvimento cursos em EaD de qualidade com rigor científico, claridade, profundidade, atualização e pertinência em função dos objetivos de aprendizagem organizado num primeiro documento que pode ser definido como projeto instrucional. Toda esta discussão organizada visa atender programas de ensino na modalidade a distância que se comprometem com o desenvolvimento de competência do individuo em sua plenitude, ou seja, aprender enquanto um ato de viver com entusiasmo.

\section{CONSIDERAÇÕES FINAIS}

O objetivo neste estudo foi apresentar diretrizes para concepção de cursos na modalidade a distância para que atendam com qualidade a proposta de desenvolvimento de competências do aprendiz. Dessa forma, não foi intenção definir um modelo único de diretrizes para a concepção de cursos de qualidade a serem ofertados na $\mathrm{EaD}$, contudo considera-se que os critérios aqui apresentados são orientativos e requerem atenção daqueles que estão iniciando na área de planejamento com foco de promover uma formação significativa, ou ainda para aqueles que atuam na área e sentem a necessidade de revisar os elementos essenciais para uma oferta que apresente compromisso com o ensinar e o aprender.

Sendo assim, sugere-se que estudos e publicações sejam ampliados nesta área de gestão e desenvolvimento de recursos educacionais, visto que se carece de elementos para iniciantes na concepção de cursos para EaD. Além disso, o compartilhamento de boas práticas para o desenvolvimento de recursos educacionais de qualidade é essencial para oferta de ensino de qualidade. Destaca-se que frente a necessidade de formação continuada, advinda da sociedade do conhecimento, elementos como objetivo de ensino e competências de formação são pilares a serem considerados como elementos mínimos de atenção. Logo, infere-se que cursos de EaD de qualidade podem apresentar diferentes desenhos em variadas combinações de recursos, processos e pessoas envolvidas. Os critérios aqui definidos são considerados referencias para 0 planejamento e oferta de uma formação que zele pela formação integral do indivíduo.

\section{REFERÊNCIAS}

AUSUBEL, D. P. The Acquisition and Retention of Knowledge: A Cognitive View. Holanda: Kluwer Academic Publishers, 2000. 
a distância. SeEaD, Brasília, 2007.

FLEURY, M. T. L.; FLEURY, A. Construindo o conceito de competências. RAC, Ed. Especial, p. 183-196, 2001.

GUIMARÃES, T. R. da C.; CARVALHO, M. de L. Planejamento e desenvolvimento de cursos em EaD. Viçosa, MG: UFV, 2015.

LEFEVRE; F.; LEFEVRE, A. M. C. Pesquisa de representação social: um enfoque qualiquantitativo: a metodologia do discurso do sujeito coletivo. 2. ed. Brasília: Liber livro, 2012.

LITTO, F. Aprendizagem a distância. São Paulo: Imprensa Oficial do Estado de São Paulo, 2010.

MARCONI, M. de A.; LAKATOS, E. M. Fundamentos de metodologia científica. 7. ed. São Paulo: Atlas, 2010.

MORAN, J. M.. A gestão da Educação a distância no Brasil. In: MIL, D.; PIMENTEL, N. M. (Org.). Educação a distância: desafios contemporâneos. São Carlos: EdUFSCar, 2010.

MORÍN, E. Os sete saberes necessários à educação do futuro. 2. ed. Brasília, DF: UNESCO, 2000.

PERRENOUD, P. Dez novas competências para ensinar. Porto Alegre: Artmed, 2000.

SILVA, A. R. L. da. Diretrizes de design instrucional para elaboração de material didático em EaD. Dissertação de mestrado. Programa de Pós-Graduação em Engenharia e Gestão do Conhecimento - UFSC, Florianópolis, 2013.

SILVA, A. R. L. da. Design educacional para gestão de mídias do conhecimento. Tese de doutorado. Programa de Pós-Graduação em Engenharia e Gestão do Conhecimento - UFSC, Florianópolis, 2017. 